\title{
Recombinant factor VIIa use in acute type A aortic dissection repair: A multicenter propensity-score-matched report from the Nordic Consortium for Acute Type A Aortic Dissection
}

Igor Zindovic, MD, ${ }^{\mathrm{a}}$ Johan Sjögren, $\mathrm{MD}, \mathrm{PhD},{ }^{\mathrm{a}}$ Anders Ahlsson, $\mathrm{MD}, \mathrm{PhD},{ }^{\mathrm{b}}$ Henrik Bjursten, MD, PhD,

Simon Fuglsang, MD, ${ }^{\mathrm{c}}$ Arnar Geirsson, $\mathrm{MD}, \mathrm{PhD},{ }^{\mathrm{d}}$ Richard Ingemansson, $\mathrm{MD}, \mathrm{PhD},{ }^{\mathrm{a}}$

Emma C. Hansson, MD, PhD, ${ }^{\mathrm{e}}$ Ari Mennander, MD, PhD, ${ }^{\mathrm{f}}$ Christian Olsson, MD, PhD, ${ }^{\mathrm{g}}$ Emily Pan, BM,

Susann Ullén, $\mathrm{PhD},{ }^{\mathrm{i}}$ Tomas Gudbjartsson, $\mathrm{MD}, \mathrm{PhD},{ }^{\mathrm{d}}$ and Shahab Nozohoor, $\mathrm{MD}, \mathrm{PhD}^{\mathrm{a}}$

\section{ABSTRACT}

Background: Surgery for acute type A aortic dissection (ATAAD) is often complicated by excessive bleeding. Recombinant factor VIIa (rFVIIa) effectively treats refractory bleeding associated with ATAAD surgery; however, adverse effects of rFVIIa in these patients have not been fully assessed. Here we evaluated rFVIIa treatment in ATAAD surgery using the Nordic Consortium for Acute Type A Aortic Dissection (NORCAAD) database.

Methods: This was a multicenter, propensity score-matched, retrospective study. Information about rFVIIa use was available for 761 patients, of whom 171 were treated with rFVIIa. We successfully matched 120 patients treated with rFVIIa with 120 controls. Primary endpoints were in-hospital mortality, postoperative stroke, and renal replacement therapy (RRT). Survival data were presented using Kaplan-Meier estimates.

Results: Compared with controls, patients treated with rFVIIa received more transfusions of packed red blood cells (median, 9.0 U [4.0-17.0 U] vs 5.0 U [2.0-11.0 U]; $P=.008$ ), platelets (4.0 U [2.0-8.0 U] vs $2.0 \mathrm{U}[1.0-4.4 \mathrm{U}] ; P<.001)$, and fresh frozen plasma (8.0 U [4.0-18.0 U] vs 5.5 U [2.0-10.3 U]; $P=.01)$ underwent reexploration for bleeding more often $(31.0 \%$ vs $16.8 \% ; P=.014)$; and had greater 24-hour chest tube output (1500 L [835-2500 mL] vs $990 \mathrm{~mL}$ [520-1720 mL]). Treatment with rFVIIa was not associated with significantly increased rates of in-hospital mortality (odds ratio [OR], 0.74; 95\% confidence interval [CI], 0.34-1.55; $P=.487$ ), postoperative stroke (OR, 1.75; 95\% CI, 0.82-3.91; $P=.163$ ), or RRT (OR, $1.18 ; 95 \% \mathrm{CI}, 0.48-2.92 ; P=.839)$.

Conclusions: In this propensity-matched cohort study of patients undergoing ATAAD surgery, treatment with rFVIIa for major bleeding was not associated with a significantly increased risk of stroke, RRT, or mortality. (J Thorac Cardiovasc Surg 2017;154:1852-9)

Despite significant surgical advances in recent years, acute type A aortic dissection (ATAAD) still poses a great clinical challenge, with high mortality and morbidity. ${ }^{1,2}$ Bleeding

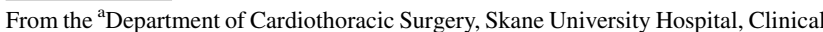
Sciences, Lund University; ${ }^{\mathrm{i}}$ Clinical Studies Sweden-Forum South, Lund; ${ }^{\mathrm{b}}$ Department of Cardiothoracic and Vascular Surgery, Orebro University Hospital and School of Health and Medicine, Orebro University, Orebro; ${ }^{\mathrm{e}}$ Department of Cardiothoracic Surgery, Sahlgrenska University Hospital and Department of Molecular and Clinical Medicine, Institute of Medicine, Sahlgrenska Academy, University of Gothenburg, Gothenburg; and ${ }^{\mathrm{g}}$ Department of Thoracic and Cardiovascular Surgery, Karolinska University Hospital, Stockholm, Sweden; ${ }^{\mathrm{c}}$ Department of Thoracic and Cardiovascular Surgery, Aarhus University Hospital, Skejby, Denmark; ${ }^{\mathrm{d}}$ Landspitali University Hospital and Faculty of Medicine, University of Iceland, Reykjavik, Iceland; ${ }^{\mathrm{f}}$ Heart Center Tampere University
}

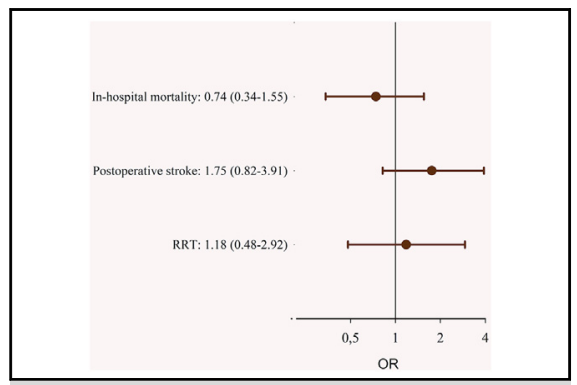

Forest plot illustrating the associations between rFVIla treatment and primary endpoints.

\section{Central Message}

The results of this study showed that patients undergoing rFVIIa treatment in association to ATAAD surgery did not display significantly greater rates of mortality, renal replacement therapy or stroke.

\section{Perspective}

In previous studies on standard and complex cardiac surgery, use of recombinant factor VIIa (rFVIIa) has been associated with increased rates of mortality and stroke. In this study of a large sample of patients undergoing acute type A aortic dissection surgery, treatment with rFVIIa for major bleeding was not associated with a significantly increased risk of stroke, the need for renal replacement therapy (RRT), or mortality.

See Editorial Commentary page 1860. complications related to cardiac surgery adversely affect surgical outcomes. ${ }^{3,4}$ The pathology of aortic dissection is known to cause dysregulation of the

Hospital, Tampere; and ${ }^{\mathrm{h}}$ Heart Center, Turku University Hospital and University of Turku, Turku, Finland.

Funding for this work was provided by the University of Iceland Research Fund, the Landspitali Research Fund, and the Mats Kleberg Foundation.

Received for publication March 24, 2017; revisions received July 4, 2017; accepted for publication Aug 5, 2017; available ahead of print Sept 26, 2017.

Address for reprints: Igor Zindovic, MD, Department of Cardiothoracic Surgery, Skane University Hospital, Lund SE-221 85, Sweden (E-mail: igor.zindovic@ med.lu.se).

$0022-5223 / \$ 36.00$

Copyright (C) 2017 by The American Association for Thoracic Surgery http://dx.doi.org/10.1016/j.jtcvs.2017.08.020 


$\begin{array}{ll}\text { Abbreviations and Acronyms } \\ \text { ATAAD } & =\text { acute type A aortic dissection } \\ \text { BMI } & =\text { body mass index } \\ \text { CI } & =\text { confidence interval } \\ \text { COPD } & =\text { chronic obstructive pulmonary } \\ & \text { disease } \\ \text { CPB } & =\text { cardiopulmonary bypass } \\ \text { FFP } & =\text { fresh frozen plasma } \\ \text { HCA } & =\text { hypothermic circulatory arrest } \\ \text { IQR } & =\text { interquartile range } \\ \text { MI } & =\text { myocardial infarction } \\ \text { NORCAAD }= & \text { Nordic Consortium for Acute Type A } \\ & \text { Aortic Dissection } \\ \text { OR } & =\text { odds ratio } \\ \text { PRBC } & =\text { packed red blood cells } \\ \text { rFVIIa } & =\text { recombinant factor VIIa } \\ \text { RRT } & =\text { renal replacement therapy }\end{array}$

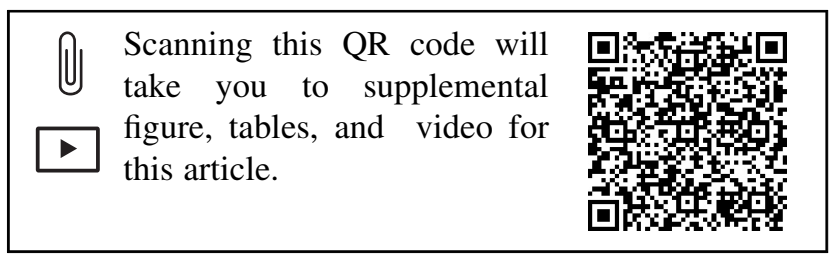

coagulation system, augmented by cardiopulmonary bypass (CPB) and deep hypothermia. ${ }^{5-7}$ Consequently, massive intraoperative and postoperative bleeding is a feared complication associated with considerably elevated morbidity and mortality. ${ }^{8,9}$

Since first described in 2001, ${ }^{10}$ recombinant factor VIIa (rFVIIa) (Novoseven; Novo Nordisk A/S, Bagsvaerd, Denmark) has gained increasing use for treating refractory bleeding in the off-label setting of cardiothoracic surgery. Previous studies have reported that rFVIIa effectively reduces blood loss and the need for allogeneic blood transfusions in standard cardiac surgery ${ }^{11,12}$; however, questions have been raised as to whether the prothrombotic properties of rFVIIa lead to an increased risk of thromboembolic complications when used in patients without hemophilia. ${ }^{13,14}$ Data on the use of rFVIIa in ATAAD surgery are scarce, and previous studies are limited by small sample sizes. ${ }^{11,15}$

The Nordic Consortium for Acute Type A Aortic Dissection (NORCAAD) is a joint database consisting of 1159 patients who underwent surgery for ATAAD at 8 tertiary centers in Denmark, Finland, Iceland, and Sweden between 2005 and $2014 .{ }^{16}$ In the present study, we used the NORCAAD database to evaluate the effect of rFVIIa on mortality and rates of postoperative stroke and renal replacement therapy (RRT) after ATAAD surgery.

\section{METHODS}

This study was approved by the Institutional Review Board of each participating center.

\section{Study Design}

This was a multicenter, propensity score-matched study using data collected retrospectively from the NORCAAD database for patients who underwent ATAAD surgery between January 1, 2005, and December 31, 2014, at 8 Nordic centers. A total of 194 clinical variables were collected from 1159 patients, including demographic data, previous medical history, preoperative medications, clinical symptoms on presentation, diagnostic methods, operative variables, complications, bleeding and blood transfusions, laboratory values, and outcome data. ${ }^{16}$

Primary endpoints were in-hospital mortality, perioperative stroke, and RRT. Secondary endpoints were reexploration for bleeding and long-term mortality. In-hospital mortality was defined as death occurring during the hospital stay. Stroke was defined as a clinically significant loss of neurologic function caused by an ischemic event with or without confirmation by computed tomography scan. RRT was defined as the postoperative need for continuous venovenous hemofiltration or hemodialysis.

Postoperative bleeding was defined as total chest tube output volume during the first 24 hours after surgery. Postoperative cardiac tamponade was defined as pericardial effusion necessitating pericardial drainage or reexploration. Transfusions were reported as units of packed red blood cells (PRBCs), platelets, or fresh frozen plasma (FFP), administered at any time during the hospital stay.

\section{Surgical Procedures}

The decision to operate for ATAAD and the specific techniques used were at the discretion of the responsible surgeons at each center. Standard median sternotomy, $\mathrm{CPB}$, and intermittent cardioplegic arrest were routinely used as described previously. ${ }^{16}$ Cannulation sites varied by center, patient, and surgeon. In cases where a cross-clamp was not used, resection and inspection of the aortic arch were performed with the patient under deep $\left(<20^{\circ} \mathrm{C}\right)$ or moderate $\left(21^{\circ} \mathrm{C}-32^{\circ} \mathrm{C}\right)$ hypothermic circulatory arrest, with or without the use of antegrade cerebral perfusion.

The method of ascending aorta or aortic arch replacement depended on the location of the intimal tear and the extent of dissection. Root replacement was performed when the tear involved the coronary ostia or aortic valve, or in the presence of an aortic root aneurysm. Operations that involved the aortic arch entailed reimplantation of any supra-aortic branch. When required, the competence of the aortic valve was restored as feasible via subcommissural plication, commissural resuspension, or valvuloplasty. Concomitant procedures (eg, coronary artery bypass) were performed when required.

Management of intraoperative and postoperative bleeding varied depending on the center and time. However, rFVIIa was used mainly during surgery or in the intensive care unit when primary pharmacologic treatment to reduce bleeding had failed.

\section{Statistical Analysis}

Categorical variables were expressed as number and percentage, and continuous variables are presented as median and interquartile range (IQR). A propensity analysis was performed to adjust for differences between the 2 groups. ${ }^{17}$ As a first step, univariate logistic regression analyses with group as outcome were performed for all variables listed in Table 1 . All variables with a $P$ value $<.20$ were subsequently included in the multivariable logistic regression model, which computed the propensity scores. These variables were bicuspid aortic valve, previous cardiac surgery, history of stroke, cerebral malperfusion, Penn class, proximal surgical technique, CPB and cross-clamp times, and lowest core temperature. A nearest-neighbor matching with caliper 0.2 was 
TABLE 1. Baseline and surgical characteristics in the unmatched populations

\begin{tabular}{|c|c|c|c|c|c|}
\hline Characteristic & rFVIIa $(n=171)$ & Control $(\mathbf{n}=\mathbf{5 9 0})$ & AbSD, $\%$ & $P$ value & Missing, $\mathbf{n}$ \\
\hline Age, y, median (IQR) & $62.0(54.0-68.0)$ & $64.0(53.6-70.8)$ & 3.9 & .65 & 0 \\
\hline Male sex, n (\%) & $122(71.3)$ & $394(66.8)$ & 9.8 & .26 & 0 \\
\hline Hypertension, n (\%) & $89(52.0)$ & $311(52.7)$ & 1.3 & .88 & 0 \\
\hline History of aortic aneurysm, n (\%) & $20(11.7)$ & $51(8.7)$ & 10.3 & .24 & 4 \\
\hline Connective tissue disease, $\mathrm{n}(\%)$ & $3(1.8)$ & $20(3.4)$ & 9.6 & .28 & 3 \\
\hline Bicuspid aortic valve, n (\%) & $6(3.5)$ & $39(6.7)$ & 13.6 & .13 & 10 \\
\hline Previous aortic surgery, n (\%) & $7(4.1)$ & $14(2.4)$ & 10.3 & .24 & 6 \\
\hline Previous cardiac surgery, $\mathrm{n}(\%)$ & $7(4.1)$ & $12(2.0)$ & 13.2 & .14 & 0 \\
\hline Diabetes mellitus, n (\%) & $4(2.3)$ & $12(2.0)$ & 2.0 & .82 & 4 \\
\hline Hyperlipidemia, n (\%) & $16(9.4)$ & $74(12.6)$ & 9.9 & .26 & 4 \\
\hline History of stroke, n (\%) & $10(5.8)$ & $17(2.9)$ & 16.0 & .07 & 3 \\
\hline Chronic kidney disease, n (\%) & $5(2.9)$ & $9(1.5)$ & 10.3 & .24 & 3 \\
\hline COPD, n (\%) & $8(4.7)$ & $33(5.6)$ & 4.2 & .63 & 4 \\
\hline History of smoking, $\mathrm{n}(\%)$ & $62(45.9)$ & $181(41.7)$ & 8.5 & .39 & 192 \\
\hline BMI, kg/m², median (IQR) & $25.4(23.5-28.2)$ & $26.0(23.5-29.0)$ & 9.3 & .32 & 96 \\
\hline Aspirin, n (\%) & $52(30.4)$ & $155(26.5)$ & 8.9 & .31 & 4 \\
\hline Other antiplatelet treatment, $\mathrm{n}(\%)$ & $23(13.5)$ & $61(10.4)$ & 9.7 & .27 & 4 \\
\hline Warfarin treatment, $\mathrm{n}(\%)$ & $16(9.4)$ & $38(6.5)$ & 11.2 & .20 & 4 \\
\hline Blood pressure medicine, $\mathrm{n}(\%)$ & $70(41.7)$ & $255(44.2)$ & 5.1 & .56 & 16 \\
\hline Organ malperfusion (any), n (\%) & $51(30.0)$ & $152(26.0)$ & 9.0 & .31 & 7 \\
\hline Cerebral malperfusion, n (\%) & $20(12.9)$ & $39(8.1)$ & 16.4 & .08 & 127 \\
\hline DeBakey type $1, \mathrm{n}(\%)$ & $130(76.5)$ & $435(74.2)$ & 5.2 & .55 & 5 \\
\hline Intramural hematoma, n (\%) & $15(9.0)$ & $55(9.5)$ & 1.7 & .85 & 18 \\
\hline Penn class, n (\%) & & & 24.3 & .07 & 9 \\
\hline Aa & $97(57.1)$ & $385(66.2)$ & & & \\
\hline $\mathrm{Ab}$ & $40(23.5)$ & $122(21.0)$ & & & \\
\hline Ac & $20(11.8)$ & $54(9.3)$ & & & \\
\hline $\mathrm{Abc}$ & $13(7.6)$ & $21(3.6)$ & & & \\
\hline Proximal surgical technique, n (\%) & & & 30.4 & .01 & 1 \\
\hline Supracoronary graft & $108(63.2)$ & 447 (75.9) & & & \\
\hline Bentall procedure & $46(26.9)$ & $104(17.7)$ & & & \\
\hline David/Yacoub procedures & $4(2.4)$ & $14(2.4)$ & & & \\
\hline Other & $13(7.6)$ & $24(4.1)$ & & & \\
\hline Distal surgical technique, $(\%)$ & & & 13.3 & .48 & 8 \\
\hline Ascending aorta & $130(76.5)$ & $418(71.7)$ & & & \\
\hline Hemiarch procedure & $33(19.4)$ & $126(21.6)$ & & & \\
\hline Arch procedure & $5(2.9)$ & $31(5.3)$ & & & \\
\hline Other & $2(1.2)$ & $8(1.4)$ & & & \\
\hline CPB time, min, median (IQR) & $211.5(173.2-267.8)$ & $189.0(153.0-228.0)$ & 38.7 & $<.001$ & 60 \\
\hline Cross-clamp time, min, median (IQR) & $99.5(69.5-145.8)$ & $87.0(65.0-123.5)$ & 25.9 & .005 & 84 \\
\hline HCA time, min, median (IQR) & $24.0(16.0-32.0)$ & $25.0(18.0-34.0)$ & 12.0 & .24 & 75 \\
\hline Lowest core temperature, ${ }^{\circ} \mathrm{C}$, median (IQR) & $18.0(18.0-21.0)$ & $20.0(18.0-24.0)$ & 40.5 & $<.001$ & 56 \\
\hline
\end{tabular}

$r F V I I a$, Recombinant factor VIIa; $A b S D$, absolute standardized difference; $I Q R$, interquartile range; $C O P D$, chronic obstructive pulmonary disease; $B M I$, body mass index; $C P B$, cardiopulmonary bypass; $H C A$, hypothermic circulatory arrest. 
performed using the propensity scores. This resulted in the matching of 120 out of a maximum of 127 possible pairs. The remaining patients did not have the data required for inclusion in the model. The matching was evaluated using standardized mean differences.

The paired samples were compared using conditional logistic regression for binary variables. Comparisons of the primary endpoints were presented as odds ratios (ORs) with $95 \%$ confidence intervals (CIs), and were illustrated using forest plots. Note that these ORs were given by the conditional logistic regression and were based on the discordant pairs. The McNemar-Bowker test was used for categorical variables with more than two categories. All continuous variables in the matched sample met the conditions for a paired $t$ test, which was subsequently used for analysis. The original unpaired sample was compared using the Fisher's exact test for categorical variables and the Mann-Whitney $U$ test for continuous variables.

Late survival was calculated using Kaplan-Meier estimates, and the groups were compared using the log-rank test. A stratified version was applied for the paired samples. Statistical analyses were performed using $\mathrm{R}$ version 3.2.5. ( $\mathrm{R}$ Project for Statistical Computing; https://www.rproject.org/), and the MatchIt package in $\mathrm{R}$ (https://cran.r-project.org/ web/packages/MatchIt/index.html) was used for propensity matching.

\section{RESULTS}

\section{Study Population and Follow-up}

A total of 1159 patients were included in the NORCAAD database up to March 2017. Follow-up was performed in January 2015 and was $99.5 \%$ complete, with a median follow-up time of 2.3 years (range, 0.25-5.23 years). Data on the use of rFVIIa was available for 761 patients (99.5\% complete; median follow-up time of 2.2 years; IQR, 0.59-4.63 years). Of these 761 patients, 171 received treatment with rFVIIa (rFVIIa group).

\section{Unmatched Population}

The baseline characteristics and intraoperative data for the unmatched groups are presented in Table 1. Compared with the control group, the rFVIIa group had a more frequent history of stroke $(5.8 \%$ vs $2.9 \% ; P=.07)$ and cerebral malperfusion $(12.9 \%$ vs $8.1 \% ; P=.08)$. Patients in the rFVIIa group more frequently underwent complex aortic root surgery $(P=.01)$, had longer median durations of CPB (212 minutes [IQR, 173-268 minutes] vs 189 [IQR, 153-228 minutes]; $P<.001)$ and cross-clamp time (100 minutes [IQR, 70-146 minutes] vs 87 minutes [IQR, 65-124 minutes]; $P=.005$ ), and had a lower median core temperature nadir $\left(18^{\circ} \mathrm{C}\left[\mathrm{IQR}, 18^{\circ} \mathrm{C}-21^{\circ} \mathrm{C}\right]\right.$ vs $20^{\circ} \mathrm{C}$ $\left.\left[\mathrm{IQR}, 18^{\circ} \mathrm{C}-24^{\circ} \mathrm{C}\right] ; P<.001\right)$. The outcome results for the unmatched population are presented in the Supplementary Materials.

\section{Matched Population}

The propensity score algorithm successfully matched 120 patients who received rFVIIa with 120 control patients. The baseline characteristics and intraoperative data for the matched groups are presented in Table 2 . After propensity score matching, there were no significant differences between the groups, except in preoperative warfarin treatment $(11.7 \%$ vs $4.2 \% ; P=.049)$.

A sensitivity analysis of the primary outcomes was performed adjusting for all variables with a standardized absolute difference exceeding $10 \%$. The variables were adjusted for in the conditional logistic regression of the matched dataset, which resulted in minor effects on the ORs, but with no impact on the conclusions of our main analyses.

To further evaluate the propensity score matching, we performed a multivariable logistic regression adjusting for the same variables as those included in the propensity score matching. Even after this adjustment, we found no significant effect on between-group differences in the primary outcomes.

\section{Transfusions and Reexploration for Bleeding}

Patients in the rFVIIa group had greater chest tube output during the first 24 hours than controls (mean, $1500 \mathrm{~mL}$ [IQR, 835-2500 mL] vs $990 \mathrm{~mL}$ [IQR, 520-1720 mL]); however, a comparative analysis of chest tube output between the matched groups was not possible owing to numerous missing values (Table 3 ). In the unmatched samples, data were available for 444 of 761 patients, demonstrating that patients who received rFVIIa bled significantly more during the first 24 hours (median, $1160 \mathrm{~mL}$ [IQR, 670-2215 mL] vs $780 \mathrm{~mL}$ [IQR, 520-1230 mL]; $P<.001$ ) (Table E2). Compared with control patients, patients treated with rFVIIa received a median of $5 \mathrm{mg}$ (IQR, 2-10 mg) of rFVIIa; received more transfusions of PRBCs (median, 9.0 U [IQR, 4.0-17.0 U] vs 5.0 U [IQR, 2.0-11.0 U]; $P=.008$ ), platelets (median, $4.0 \mathrm{U}$ [IQR, 2.0-8.0 U] vs $2.0 \mathrm{U}$ [IQR, 1.0-4.4 U]; $P<.001$ ), and FFP (median, $8.0 \mathrm{U}$ [IQR, 4.0-18.0 U] vs 5.5 U [IQR, 2.0-10.3 U]; $P=.010$ ); and were treated with more fibrinogen concentrate (median, $2.0 \mathrm{~g}$ [IQR, 2.0-6.0 g] vs $0.0 \mathrm{~g}$ [IQR, 0.0-2.0 g; $P<.001)$. Patients in the rFVIIa group had more frequent postoperative tamponade $(23.9 \%$ vs $9.7 \%: P=.011)$ and reexploration for bleeding $(31.0 \%$ vs $16.8 \% ; P=.014)$.

\section{Early Mortality and Postoperative Complications}

Comparisons between the rFVIIa and control groups for the primary outcomes showed no significant differences in in-hospital mortality (OR, $0.74 ; 95 \%$ CI, 0.34-1.55; $P=.487$ ), postoperative stroke (OR, $1.75 ; 95 \% \mathrm{CI}$, $0.82-3.91 ; P=.163)$, or RRT (OR, $1.18 ; 95 \% \mathrm{CI}$, $0.48-2.92 ; P=.839$ ) (Figure 1 ). The binary results for early mortality and postoperative complications are shown in Table 4. In-hospital mortality was $12.5 \%$ in the rFVIIa group and $16.7 \%$ in the control group $(P=.486)$, whereas 30 -day mortality in the two groups was $15.8 \%$ and $18.3 \%$, respectively $(P=.743)$. The postoperative stroke rate was $25.6 \%$ in the rFVIIa group and $17.9 \%$ in the control group 
TABLE 2. Baseline and surgical characteristics in the propensity-score-matched populations

\begin{tabular}{|c|c|c|c|c|c|}
\hline Characteristic & rFVIIa $(n=120)$ & Control $(\mathbf{n}=120)$ & AbSD, $\%$ & $P$ value & Missing, $\mathbf{n}$ \\
\hline Age, y, median (IQR) & $62(54.8-69.0)$ & $62(49.0-68.8)$ & 16.2 & .22 & 0 \\
\hline Male sex, n (\%) & $83(69.2)$ & $74(61.7)$ & 16.1 & .25 & 0 \\
\hline Hypertension, $\mathrm{n}(\%)$ & $60(50.0)$ & $68(56.7)$ & 13.4 & .34 & 0 \\
\hline History of aortic aneurysm, n ( $\%)$ & $14(11.7)$ & $11(9.2)$ & 8.6 & .66 & 0 \\
\hline Connective tissue disease, $\mathrm{n}(\%)$ & $2(1.7)$ & $5(4.2)$ & 14.6 & .45 & 0 \\
\hline Bicuspid aortic valve, $\mathrm{n}(\%)$ & $5(4.2)$ & $5(4.2)$ & $<0.1$ & 1.00 & 0 \\
\hline Previous aortic surgery, $\mathrm{n}(\%)$ & $6(5.0)$ & $5(4.2)$ & 5.1 & 1.00 & 0 \\
\hline Previous cardiac surgery, $\mathrm{n}(\%)$ & $4(3.3)$ & $2(1.7)$ & 10.7 & 69 & 0 \\
\hline Diabetes mellitus, n (\%) & $3(2.5)$ & $4(3.3)$ & 5.8 & 1.00 & 0 \\
\hline Hyperlipidemia, n (\%) & $10(8.3)$ & $9(7.5)$ & 2.6 & 1.00 & 0 \\
\hline History of stroke, n (\%) & $5(4.2)$ & $7(5.8)$ & 9.0 & .75 & 0 \\
\hline Chronic kidney disease, $\mathrm{n}(\%)$ & $5(4.2)$ & $3(2.5)$ & 12.4 & .73 & 0 \\
\hline COPD, n $(\%)$ & $5(4.2)$ & $6(5.0)$ & 3.7 & 1.00 & 0 \\
\hline History of smoking, $\mathrm{n}(\%)$ & $35(47.9)$ & $41(56.2)$ & 13.3 & .36 & 94 \\
\hline BMI, $\mathrm{kg} / \mathrm{m}^{2}$, median (IQR) & $25.1(23.4-28.1)$ & $24.8(23.4-28.1)$ & 1.0 & .64 & 50 \\
\hline Aspirin, n (\%) & $34(28.3)$ & $31(25.8)$ & 5.6 & .75 & 0 \\
\hline Anti-platelet treatment, $\mathrm{n}(\%)$ & $17(14.2)$ & $12(10.0)$ & 13.3 & .44 & 0 \\
\hline Warfarin treatment, $\mathrm{n}(\%)$ & $14(11.7)$ & $5(4.2)$ & 29.2 & .05 & 0 \\
\hline Blood pressure medicine, $\mathrm{n}(\%)$ & $48(41.0)$ & $55(47.0)$ & 14.7 & .41 & 6 \\
\hline Organ malperfusion (any), $\mathrm{n}(\%)$ & $42(35.0)$ & $44(36.7)$ & 3.8 & .89 & 0 \\
\hline Cerebral malperfusion, $\mathrm{n}(\%)$ & $14(11.7)$ & $15(12.5)$ & 2.9 & 1.00 & 0 \\
\hline DeBakey type $1, \mathrm{n}(\%)$ & $34(28.6)$ & $33(27.7)$ & 2.5 & 1.00 & 2 \\
\hline Intramural hematoma, $\mathrm{n}(\%)$ & $7(6.3)$ & $6(5.4)$ & 3.3 & 1.00 & 0 \\
\hline Penn class, n (\%) & & & 6.2 & .12 & 0 \\
\hline Аа & $68(56.7)$ & $71(59.2)$ & & & \\
\hline $\mathrm{Ab}$ & $34(28.3)$ & $31(25.8)$ & & & \\
\hline Ac & $10(8.3)$ & $10(8.3)$ & & & \\
\hline $\mathrm{Abc}$ & $8(6.7)$ & $8(6.7)$ & & & \\
\hline Proximal surgical technique, $\mathrm{n}(\%)$ & & & 13.9 & .76 & 0 \\
\hline Supracoronary graft & $77(64.2)$ & $79(65.8)$ & & & \\
\hline Bentall procedure & $30(25.0)$ & $28(23.3)$ & & & \\
\hline David/Yacoub procedure & $3(2.5)$ & $5(4.2)$ & & & \\
\hline Other & $10(8.3)$ & $8(6.7)$ & & & \\
\hline Distal surgical technique, $\mathrm{n}(\%)$ & & & 20.9 & .57 & 2 \\
\hline Ascending aorta & $86(72.3)$ & $81(68.1)$ & & & \\
\hline Hemiarch procedure & $28(23.5)$ & $27(22.7)$ & & & \\
\hline Arch procedure & $1(0.8)$ & $2(1.7)$ & & & \\
\hline Other & $4(3.4)$ & $9(7.6)$ & & & \\
\hline CPB time, min, median (IQR) & $209.5(129.0-256.5)$ & $198.0(163.5-233.5)$ & 2.6 & .82 & 0 \\
\hline Cross-clamp time, min, median (IQR) & $95.0(67.0-146.2)$ & $87.5(60.8-128.2)$ & 4.5 & .75 & 0 \\
\hline HCA time, min, median (IQR) & $25.0(17.0-32.0)$ & $27.0(20.0-36.0)$ & 14.0 & .23 & 18 \\
\hline Lowest core temperature, ${ }^{\circ} \mathrm{C}$, median (IQR) & $18.0(17.2-21.4)$ & $18.2(18.0-21.4)$ & 1.6 & .88 & 0 \\
\hline
\end{tabular}

$r F V I I a$, Recombinant factor VIIa; $A b S D$, absolute standardized difference; $I Q R$, interquartile range; $C O P D$, chronic obstructive pulmonary disease; $B M I$, body mass index; $C P B$, cardiopulmonary bypass; $H C A$, hypothermic circulatory arrest. 
TABLE 3. Intraoperative and postoperative bleeding data in the propensity score-matched populations

\begin{tabular}{lcccc}
\hline \multicolumn{1}{c}{ Characteristic } & rFVIIa $(\mathbf{n}=\mathbf{1 2 0})$ & Control $(\mathbf{n}=\mathbf{1 2 0})$ & $\boldsymbol{P}$ value & Missing, \\
\hline Bleeding in first $24 \mathrm{~h}, \mathrm{~mL}$, median (IQR) & $1500(835-2500)$ & $990(520-1720)$ & 194 \\
PRBCs, U, median (IQR) & $9.0(4.0-17.0)$ & $5.0(2.0-11.0)$ & .008 & $<.001$ \\
Platelets, U, median (IQR) & $4.0(2.0-8.0)$ & $2.0(1.0-4.4)$ & .010 \\
FFP, U, median (IQR) & $8.0(4.0-18.0)$ & $5.5(2.0-10.3)$ & 8 \\
rFVIIa, mg, median (IQR) & $5.0(2.0-10)$ & $0(0-0)$ & $0.0(0.0-2.0)$ & $<.001$ \\
Fibrinogen concentrate, g, median (IQR) & $2.0(2.0-6.0)$ & $2000(0-4000)$ & .001 \\
Tranexamic acid, U, median (IQR) & $3000(0-4000)$ & $11(9.7)$ & .138 \\
Cardiac tamponade, $\mathrm{n}(\%)$ & $27(23.9)$ & $19(16.8)$ & .011 \\
Reoperation for bleeding, $\mathrm{n}(\%)$ & $35(31.0)$ & .014 & 14 \\
\hline
\end{tabular}

$(P=.163)$, and The respective RRT rates were $12.4 \%$ and $10.6 \%(P=.839)$. A prolonged duration of mechanical ventilation was more common in the rFVIIa group than in the control group $(44.1 \%$ vs $27.0 \% ; P=.008)$.

\section{Late Mortality}

Kaplan-Meier estimates of survival are shown in Figure 2. There were no significant between-group differences in survival at 1,3 , and 5 years after surgery: $76.7 \%$ versus $76.8 \%, 74.1 \%$ versus $72.9 \%$, and $70.9 \%$ versus $70.6 \%$, respectively $(P=.248, \log$-rank test $)$.

\section{DISCUSSION}

The results of this multicenter, propensity score-matched, retrospective study demonstrated that rFVIIa treatment did not significantly increase the risk of in-hospital mortality,

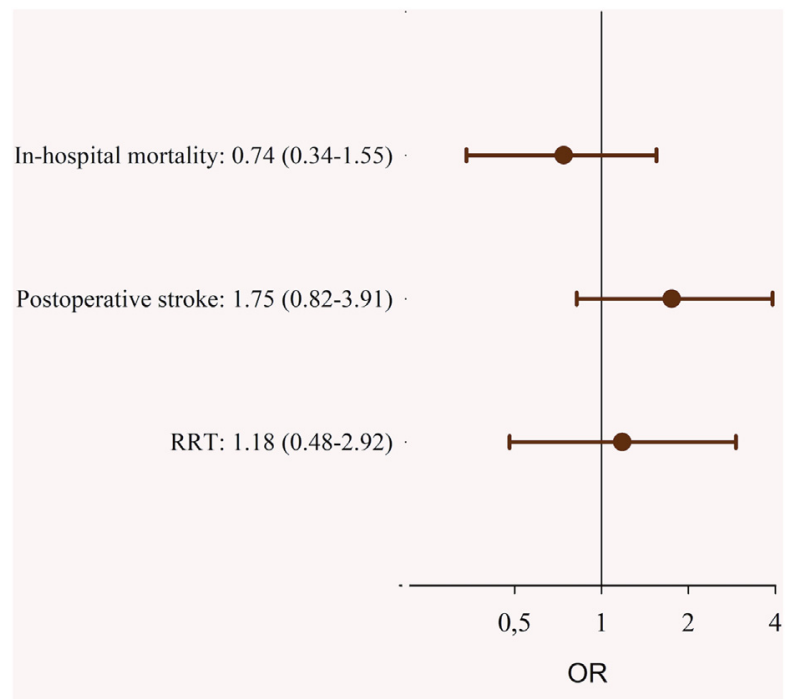

Values expressed as odds ratio (OR) with $95 \%$ confidence interval (CI). Interpretation of the OR:s is based on the discordant pairs.

RRT: renal replacement therapy.

FIGURE 1. Forest plot illustrating the associations between rFVIIa treatment and primary endpoints. stroke, or RRT after ATAAD surgery. Excessive bleeding poses a significant threat to patients undergoing ATAAD surgery. Transfusion of platelets and FFP together with prothrombin-complex concentrate, fibrinogen concentrate, and tranexamic acid have been used to prevent bleeding complications with varying degrees of success. rFVIIa was first approved in 1996 for use in patients with hemophilia, ${ }^{18}$ but over the last 15 years it has emerged as an off-label treatment of last resort for refractory bleeding after open heart surgery. Previous studies on the use of rFVIIa have described outcomes for a variety of cardiac procedures, ${ }^{12,19}$ whereas reports specifically describing the use of rFVIIa in ATAAD surgery have been limited by small sample sizes and risk of type II errors. ${ }^{11,15}$

In the present study, we did not detect any significant differences in in-hospital mortality between patients who received rFVIIa and control patients $(12.5 \%$ vs $16.7 \%$; $P=.486)$. Our results are consistent with a randomized study conducted by Gill and colleagues ${ }^{12}$ in patients undergoing coronary artery bypass grafting and mitral valve or aortic valve surgery. Two previous studies on isolated ATAAD populations did not report any differences in survival or adverse events between patients treated with rFVIIa and controls, although those studies were limited by the small number of cases ( 23 and 25 patients, respectively). ${ }^{11,15}$

In contrast, our results are not consistent with those of a previous propensity-matched analysis of patients receiving rFVIIa in association to complex cardiac surgery, where Alfirevic and colleagues ${ }^{19}$ reported impaired survival in patients treated with rFVIIa. The authors suggested that renal morbidity, possibly caused by prothrombotic effects in the renal vascular bed associated with the use of rFVIIa, could have contributed to the increased mortality. In the present study, we did not find any difference in the incidence of postoperative RRT between the two groups.

Tissue injury following aortic dissection and CPB increases the expression of tissue factor in circulating blood, which provides a substrate for thromboembolism. ${ }^{20}$ 
TABLE 4. Postoperative complications and early mortality in the propensity score-matched populations

\begin{tabular}{|c|c|c|c|c|}
\hline Characteristic & rFVIIa $(n=120)$ & Control $(n=120)$ & $P$ value & Missing, $n$ \\
\hline Postoperative stroke, n (\%) & $30(25.6)$ & $21(17.9)$ & .163 & 6 \\
\hline RRT, n (\%) & $14(12.4)$ & $12(10.6)$ & .839 & 14 \\
\hline DSWI, n (\%) & $3(2.6)$ & $5(4.3)$ & .727 & 6 \\
\hline Septicemia, n (\%) & $10(8.9)$ & $8(7.1)$ & .815 & 16 \\
\hline Ventilatory support $>48 \mathrm{~h}, \mathrm{n}(\%)$ & $49(44.1)$ & $30(27.0)$ & .008 & 18 \\
\hline Cardiac arrest, $\mathrm{n}(\%)$ & $6(5.4)$ & $7(6.3)$ & 1.000 & 16 \\
\hline Perioperative MI, n (\%) & $6(5.3)$ & $5(4.4)$ & 1.000 & 16 \\
\hline Intraoperative mortality, $\mathrm{n}(\%)$ & $2(1.7)$ & $9(7.5)$ & .065 & 0 \\
\hline 30-d mortality, n (\%) & $19(15.8)$ & $22(18.3)$ & .743 & 0 \\
\hline In-hospital mortality, n (\%) & $15(12.5)$ & $20(16.7)$ & .487 & 0 \\
\hline Late reoperation of the aorta, $\mathrm{n}(\%)$ & $4(9.5)$ & $1(2.4)$ & .453 & 156 \\
\hline
\end{tabular}

$r F V I I a$, Recombinant factor VIIa; $R R T$, renal replacement therapy; $D S W I$, deep sternal wound infection; $M I$, myocardial infarction.

This may explain why rFVIIa can cause thromboembolic complications, primarily when used in patients without hemophilia. In a meta-analysis of 6 clinical studies, Ponschab and colleagues ${ }^{14}$ reported an increased incidence of stroke in patients receiving rFVIIa, and Gill and colleagues $^{12}$ found a trend toward a higher incidence of stroke in patients undergoing standard cardiac surgery. Despite the unfavorable effects of increased bleeding volumes, transfusions, and reexploration for bleeding, in the present study we found no significant differences in the incidence of postoperative stroke between patients receiving rFVIIa and controls.

The pathology of aortic dissection causes consumptive coagulopathy, ${ }^{5}$ and surgery is often performed under deep hypothermia. Therefore, the effects of rFVIIa in routine cardiac procedures should not be extrapolated to those in

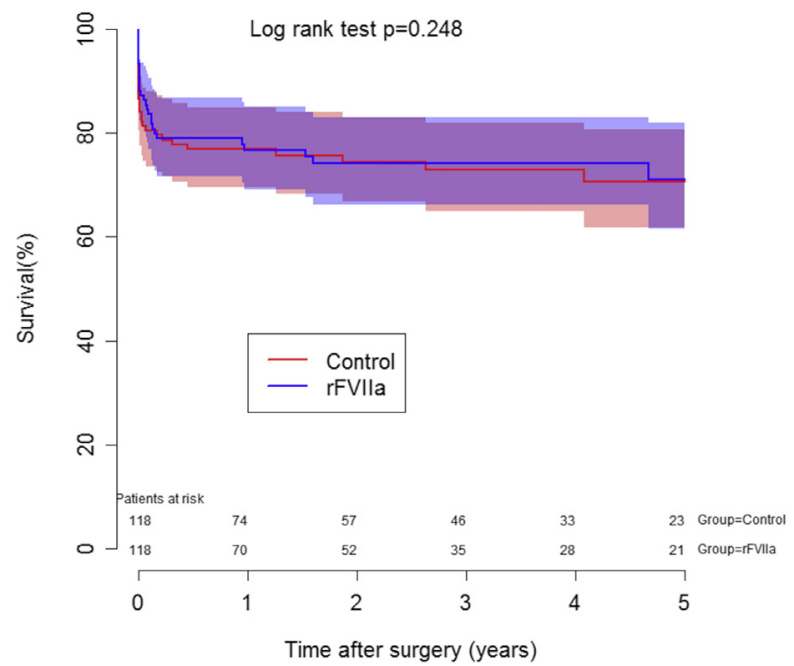

FIGURE 2. Survival curves (Kaplan-Meier method) in ATAAD patients from the matched populations, plotted by group. Late survival data were available for only 118 patients in the rFVIIa group. rFVIIa, Recombinant factor VIIa.
ATAAD surgery, and vice versa. It has previously been shown that bleeding complications in ATAAD surgery increase the incidence of adverse events and in-hospital and long-term mortality. ${ }^{8,9}$ In the present study, the patients treated with rFVIIa had significantly larger volumes of blood loss, underwent reexploration for bleeding more frequently, had greater incidence of postoperative cardiac tamponade, and received more transfusions of PRBCs, platelets, and FFP. These effects could be attributed to the fact that patients were not treated with rFVIIa unless there was significant intraoperative or postoperative bleeding. Thus, patients in the rFVIIa group were inherently at a greater risk of mortality and adverse events (including stroke and RRT) before administration of rFVIIa. Therefore, rather than increasing the risk of mortality, treatment with rFVIIa appeared to reduce the risk of adverse effects caused by excessive bleeding.

The present study has several limitations, including its retrospective design. Although to the best of our knowledge, this study is the largest analysis of rFVIIa treatment in an isolated ATAAD population reported to date. Its multicenter nature inherently introduced various surgical techniques, triggers for rFVIIa administration, and protocols for bleeding management and reexploration. The multicenter design also introduced difficulties in terms of collecting missing data. For example, rFVIIa was administered intraoperatively or in the intensive care unit, but the exact timing of rFVIIa administration was not specified in the database. The NORCAAD database enabled us to analyze a comparatively large patient population; however, the risk of type II errors cannot be overlooked. Propensity score matching is associated with a lower grade of evidence than that achieved with a randomized clinical trial. The use of propensity score matching does not control for unmeasured confounders, and missing data among the confounders might decrease the power of the study. In addition, the patients in our study received rFVIIa due to 


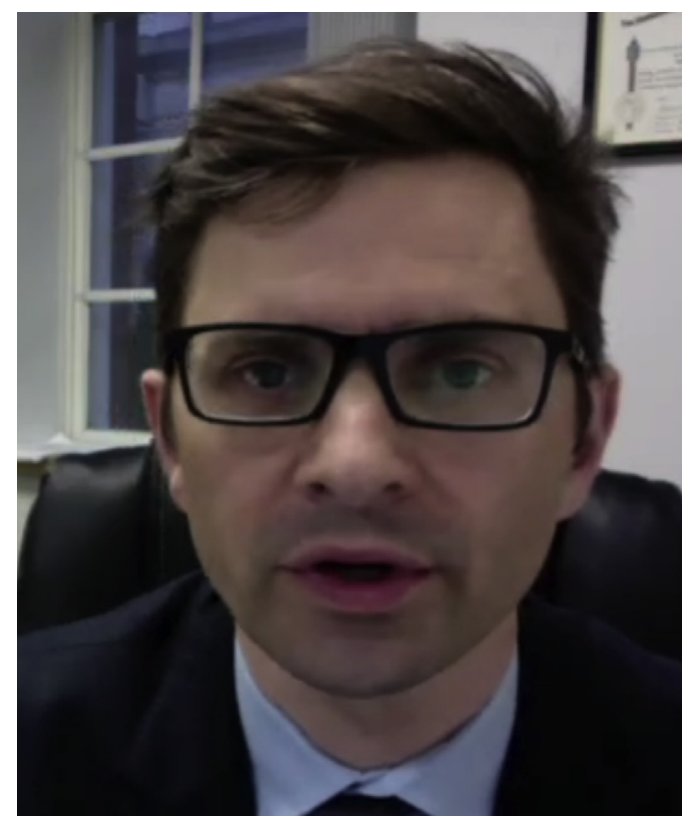

VIDEO 1. Associate Professor Arnar Geirsson, Yale University, on NORCAAD and the current study. Video available at: http://www. jtcvsonline.org/article/S0022-5223(17)31773-7/fulltext.

excessive bleeding, which led to selection bias that could have potentially skewed our findings. Administration of rFVIIa is often a treatment of last resort for refractory bleeding in ATAAD surgery; as such, it might be a surrogate for diligent efforts in achieving hemostasis. Thus, despite the efforts to eliminate confounders, the positive or negative effects of rFVIIa observed in this study cannot be attributed exclusively to the use rFVIIa.

\section{CONCLUSIONS}

This multicenter, propensity score-matched, retrospective study used data from the NORCAAD database. Our results show that despite the known adverse effects of bleeding and transfusions, patients receiving rFVIIa treatment in ATAAD surgery did not have greater early or late mortality or a significantly greater incidence of postoperative renal failure. However, this study cannot with certainty exclude an association between rFVIIa use and increased risk of postoperative stroke. Prospective, randomized, and placebo-controlled trials are needed to further define the safety and efficacy of rFVIIa in ATAAD surgery (Video 1).

\section{Conflict of Interest Statement}

Authors have nothing to disclose with regard to commercial support.

\section{References}

1. Rylski B, Suedkamp M, Beyersdorf F, Nitsch B, Hoffmann I, Blettner M, et al. Outcome after surgery for acute aortic dissection type A in patients over 70 years: data analysis from the German Registry for Acute Aortic Dissection Type A (GERAADA). Eur J Cardiothorac Surg. 2011;40:435-40.

2. Trimarchi S, Eagle KA, Nienaber CA, Rampoldi V, Jonker FH, De Vincentiis C, et al. Role of age in acute type A aortic dissection outcome: report from the International Registry of Acute Aortic Dissection (IRAD). J Thorac Cardiovasc Surg. 2010;140:784-9.

3. Unsworth-White MJ, Herriot A, Valencia O, Poloniecki J, Smith EE, Murday AJ, et al. Resternotomy for bleeding after cardiac operation: a marker for increased morbidity and mortality. Ann Thorac Surg. 1995;59:664-7.

4. Ranucci M, Bozzetti G, Ditta A, Cotza M, Carboni G, Ballotta A. Surgical reexploration after cardiac operations: why a worse outcome? Ann Thorac Surg. 2008;86:1557-62.

5. ten Cate JW, Timmers H, Becker AE. Coagulopathy in ruptured or dissecting aortic aneurysms. Am J Med. 1975;59:171-6.

6. Linden MD. The hemostatic defect of cardiopulmonary bypass. J Thromb Thrombolysis. 2003;16:129-47.

7. Wilde JT. Hematological consequences of profound hypothermic circulatory arrest and aortic dissection. J Card Surg. 1997;12(2 Suppl):201-6.

8. Hansson EC, Dellborg M, Lepore V, Jeppsson A. Prevalence, indications and appropriateness of antiplatelet therapy in patients operated for acute aortic dissection: associations with bleeding complications and mortality. Heart. 2013;99:116-21.

9. Zindovic I, Sjögren J, Bjursten H, Björklund E, Herou E, Ingemansson R, et al. Predictors and impact of massive bleeding in acute type A aortic dissection. Interact Cardiovasc Thorac Surg. 2017;24:498-505.

10. Hendriks HG, van der Maaten JM, de Wolf J, Waterbolk TW, Slooff MJ, van der Meer J. An effective treatment of severe intractable bleeding after valve repair by one single dose of activated recombinant factor VII. Anesth Analg. 2001;93: 287-9. 2nd contents page.

11. Tritapepe L, De Santis V, Vitale D, Nencini C, Pellegrini F, Landoni G, et al Recombinant activated factor VII for refractory bleeding after acute aortic dissection surgery: a propensity score analysis. Crit Care Med. 2007;35: 1685-90.

12. Gill R, Herbertson M, Vuylsteke A, Olsen PS, von Heymann C, Mythen M, et al Safety and efficacy of recombinant activated factor VII: a randomized placebo-controlled trial in the setting of bleeding after cardiac surgery. Circulation. 2009;120:21-7.

13. O'Connell KA, Wood JJ, Wise RP, Lozier JN, Braun MM. Thromboembolic adverse events after use of recombinant human coagulation factor VIIa. JAMA 2006;295:293-8.

14. Ponschab M, Landoni G, Biondi-Zoccai G, Bignami E, Frati E, Nicolotti D, et al Recombinant activated factor VII increases stroke in cardiac surgery: a meta-analysis. J Cardiothorac Vasc Anesth. 2011;25:804-10.

15. Yan W, Xuan C, Ma G, Zhang L, Dong N, Wang Z, et al. Combination use of platelets and recombinant activated factor VII for increased hemostasis during acute type A dissection operations. J Cardiothorac Surg. 2014;9: 156-63.

16. Geirsson A, Ahlsson A, Franco-Cereceda A, Fuglsang S, Gunn J, Hansson EC et al. The Nordic Consortium for Acute type A Aortic Dissection (NORCAAD): objectives and design. Scand Cardiovasc J. 2016;50:334-40.

17. Austin PC. An introduction to propensity score methods for reducing the effects of confounding in observational studies. Multivariate Behav Res. 2011;46: 399-424.

18. Hedner U. Mechanism of action of factor VIIa in the treatment of coagulopathies Semin Thromb Hemost. 2006;32(Suppl 1):77-85.

19. Alfirevic A, Duncan A, You J, Lober C, Soltesz E. Recombinant factor VII is associated with worse survival in complex cardiac surgical patients. Ann Thorac Surg. 2014;98:618-24.

20. Ernofsson M, Thelin S, Siegbahn A. Monocyte tissue factor expression, cel activation, and thrombin formation during cardiopulmonary bypass: a clinical study. J Thorac Cardiovasc Surg. 1997;113:576-84.

Key Words: aorta, aneurysm, dissecting, hemorrhage 


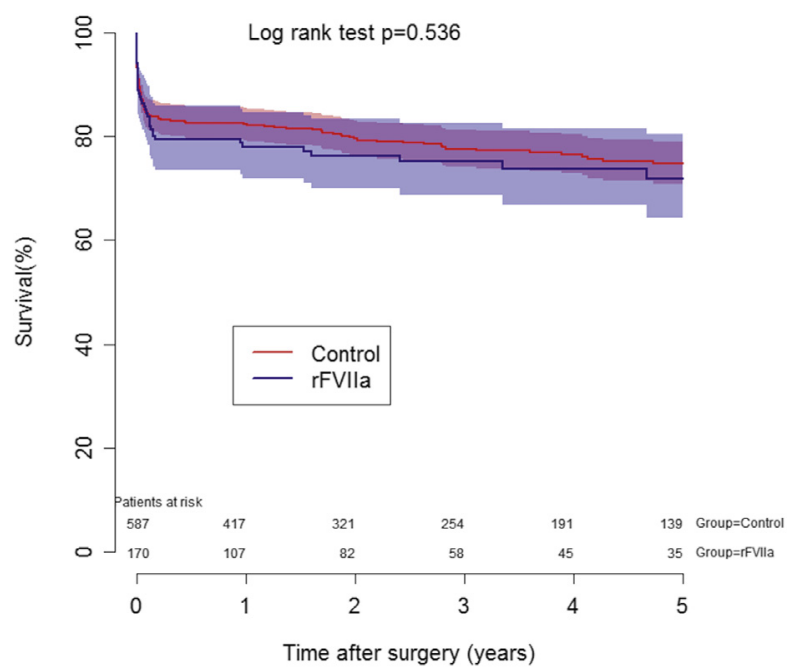

FIGURE E1. Survival curves (Kaplan-Meier method) in ATAAD patients from the unmatched populations, plotted by group. rFVIIa, Recombinant factor VIIa.

TABLE E1. Primary outcomes in the unmatched populations

\begin{tabular}{lccc}
\hline \multicolumn{1}{c}{ Outcome } & $\begin{array}{c}\text { rFVIIa } \\
(\mathbf{n}=\mathbf{1 7 1}), \\
\mathbf{n}(\%)\end{array}$ & $\begin{array}{c}\text { Control } \\
(\mathbf{n}=\mathbf{5 9 0}), \\
\mathbf{n}(\%)\end{array}$ & $\begin{array}{c}\text { OR } \\
(\mathbf{9 5} \% \mathbf{C I})\end{array}$ \\
\hline In-hospital mortality & $23(13.5)$ & $78(13.2)$ & $1.02(0.58-1.72)$ \\
Postoperative stroke & $44(26.0)$ & $100(17.2)$ & $1.69(1.09-2.58)$ \\
$\begin{array}{l}\text { Renal replacement } \\
\text { therapy }\end{array}$ & $36(21.3)$ & $59(10.2)$ & $2.37(1.45-3.82)$ \\
\hline$r F V I I a$, Recombinant factor VIIa; $O R$, odds ratio; $C I$, confidence interval.
\end{tabular}


TABLE E2. Intraoperative and postoperative bleeding data in the unmatched populations

\begin{tabular}{|c|c|c|c|c|}
\hline Variable & $\operatorname{rFVIIa}(n=171)$ & Control $(\mathbf{n}=\mathbf{5 9 0})$ & $P$ value & Missing, $\mathbf{n}$ \\
\hline Bleeding in first $24 \mathrm{~h}, \mathrm{~mL}$, mean (IQR) & $1160(670-2215)$ & $780(520-1230)$ & $<.001$ & 317 \\
\hline PRBCs, U, mean (IQR) & $10.0(5-22)$ & $5.0(2.0-10.0)$ & $<.001$ & 22 \\
\hline Platelets, U, mean (IQR) & $4.0(2.0-9.0)$ & $2.0(1.0-4.0)$ & $<.001$ & 13 \\
\hline FFP, U, mean (IQR) & $9.0(4.0-22.0)$ & $4.4(2.0-9.0)$ & $<.001$ & 24 \\
\hline rFVIIa, mean (IQR) & $5.0(2.0-10)$ & $0(0-0)$ & $<.001$ & 0 \\
\hline Fibrinogen concentrate, g, mean (IQR) & $2.0(1.0-6.0)$ & $0.0(0.0-2.0)$ & $<.001$ & 9 \\
\hline Tranexamic acid, U, mean (IQR) & $3260(0-4000)$ & $4000(0-4000)$ & .874 & 44 \\
\hline Cardiac tamponade, $\mathrm{n}(\%)$ & $43(25.4)$ & $63(10.9)$ & $<.001$ & 15 \\
\hline Reoperation for bleeding, $\mathrm{n}(\%)$ & $57(33.7)$ & $92(16.0)$ & $<.001$ & 17 \\
\hline
\end{tabular}

$r F V I I a$, Recombinant factor VIIa; $I Q R$, interquartile range; $P R B C$, packed red blood cell; $F F P$, fresh frozen plasma.

TABLE E3. Postoperative complications and early mortality in the unmatched populations

\begin{tabular}{|c|c|c|c|c|}
\hline Outcome & rFVIIa $(n=171)$, n $(\%)$ & Control $(\mathrm{n}=590), \mathrm{n}(\%)$ & $P$ value & Missing, $\mathbf{n}$ \\
\hline Postoperative stroke & $44(26.0)$ & $100(17.2)$ & .014 & 12 \\
\hline RRT & $36(21.3)$ & $59(10.2)$ & $<.001$ & 16 \\
\hline DSWI & $4(2.4)$ & $11(1.9)$ & .756 & 13 \\
\hline Septicemia & $25(14.9)$ & $68(11.8)$ & .290 & 16 \\
\hline Ventilatory support $>48 \mathrm{~h}$ & $83(49.4)$ & $133(23.5)$ & $<.001$ & 27 \\
\hline Cardiac arrest & $14(8.3)$ & $22(3.9)$ & .025 & 24 \\
\hline Perioperative MI & $10(5.9)$ & $31(5.4)$ & .848 & 13 \\
\hline Intraoperative mortality & $2(1.2)$ & $33(5.6)$ & .012 & 0 \\
\hline 30-d mortality & $26(15.2)$ & $91(15.4)$ & 1.000 & 0 \\
\hline In-hospital mortality & $23(13.5)$ & $78(13.2)$ & .899 & 0 \\
\hline Late reoperation of the aorta & $9(9.3)$ & $20(5.7)$ & .242 & 313 \\
\hline
\end{tabular}

rFVIIa, Recombinant factor VIIa; RRT, renal replacement therapy; DSWI, deep sternal wound infection; MI, myocardial infarction. 